\title{
Surgical Management of Pierre Robin Sequence: Using Mandibular Distraction Osteogenesis to Address Hypoventilation and Failure to Thrive in Infancy
}

Andrew R. Scott, MD, FACS ${ }^{1}$

${ }^{1}$ Department of Otolaryngology and Pediatrics, Tufts University School of Medicine, Cleft Lip and Palate Clinic, Floating Hospital for Children at Tufts Medical Center, Boston, Massachusetts

Address for correspondence Andrew R. Scott, MD, FACS, Department of Otolaryngology and Facial Plastic Surgery, Floating Hospital for Children at Tufts Medical Center, 800 Washington St., Box 850, Boston MA 02111 (e-mail: ascott@tuftsmedicalcenter.org).

Facial Plast Surg 2016;32:177-187.

\begin{abstract}
Keywords

- micrognathia

- distraction osteogenesis

- airway obstruction

- craniofacial

Mandibular hypoplasia may present in isolation or in the context of glossoptosis and a U-shaped, incomplete cleft palate. This latter triad is referred to as Pierre Robin sequence. Deleterious effects of micrognathia that may present during infancy are due primarily to glossoptosis or posterior displacement of the tongue. This tongue base prolapse may cause varying degrees of upper airway obstruction. A surgical option for management of tongue base airway obstruction secondary to mandibular hypoplasia is neonatal mandibular distraction osteogenesis. Herein, the author seeks to outline the benefits and limitations of early mandibular distraction osteogenesis as a way of managing airway obstruction and feeding difficulty in newborns with micrognathia. A description of the author's operative technique as well as potential complications and pitfalls will also be discussed.
\end{abstract}

Micrognathia is a craniofacial deformity defined by a small mandible in which the mandibular alveolus is significantly posterior to the maxillary alveolus. Mandibular hypoplasia may present in isolation or in the context of glossoptosis and a U-shaped, incomplete cleft palate. This latter triad is referred to as Pierre Robin sequence (PRS) (-Fig. 1).

Deleterious effects of micrognathia that may present during infancy are due primarily to glossoptosis or posterior displacement of the tongue. This tongue base prolapse may cause varying degrees of upper airway obstruction, complicating coordination of swallowing, and when severe, preventing adequate ventilation, even at rest.

Surgical interventions for micrognathia have the shared goal of ameliorating or bypassing tongue base obstruction. Glossopexy procedures such as tongue lip adhesion (TLA) may be performed to pull the tongue forward and open the pharyngeal airway. Another procedure, tracheotomy, allows for complete bypass of any form of upper airway obstruction.
Another surgical option for management of tongue base airway obstruction secondary to mandibular hypoplasia is neonatal mandibular distraction osteogenesis (MDO). Distraction osteogenesis is a technique in which a bone is gradually lengthened following an initial osteotomy. Following a short latency period after the initial osteotomy, the bone segments are separated by small increments and induction of new bone formation takes place within the gap. During this "activation phase," the segments are separated until the desired lengthening has been achieved. Next a consolidation period ensues in which the bone segments are held securely in their advanced position. The immature bone (referred to as "the regenerate") ossifies during this consolidation phase, after which the distraction hardware is removed under a second anesthetic. As distraction proceeds at a slow pace, related muscles, blood vessels, nerves, skin, and mucosa are also elongated during the process (-Figs. 2 and $\mathbf{3}$ ).
Issue Theme Congenital Deformities of the Face, Head, and Neck; Guest Editor, Travis T. Tollefson, MD, MPH, FACS
Copyright $\odot 2016$ by Thieme Medical Publishers, Inc., 333 Seventh Avenue, New York, NY 10001, USA. Tel: +1(212) 584-4662.
DOI http://dx.doi.org/ 10.1055/s-0036-1581050. ISSN 0736-6825. 

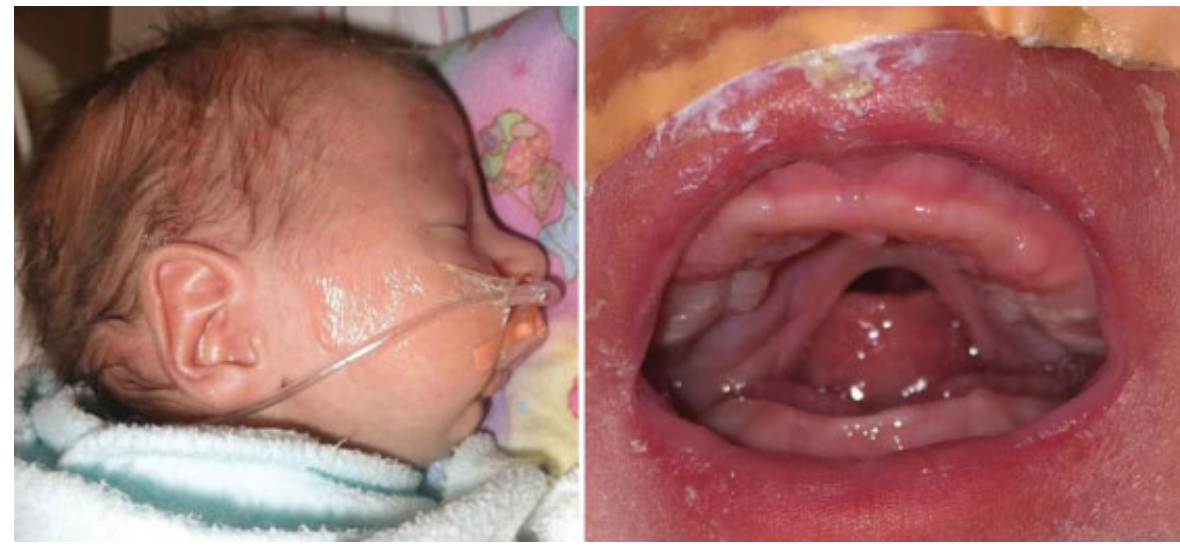

Fig. 1 An example of isolated Pierre Robin sequence. Note that along with micrognathia apparent on facial profile, there is glossoptosis, with the tongue prolapsed into the incomplete cleft in the palate.

Herein, the author seeks to outline the benefits and limitations of early MDO as a way of managing airway obstruction and feeding difficulty in newborns with micrognathia. A description of the author's operative technique as well as potential complications and pitfalls will also be discussed.
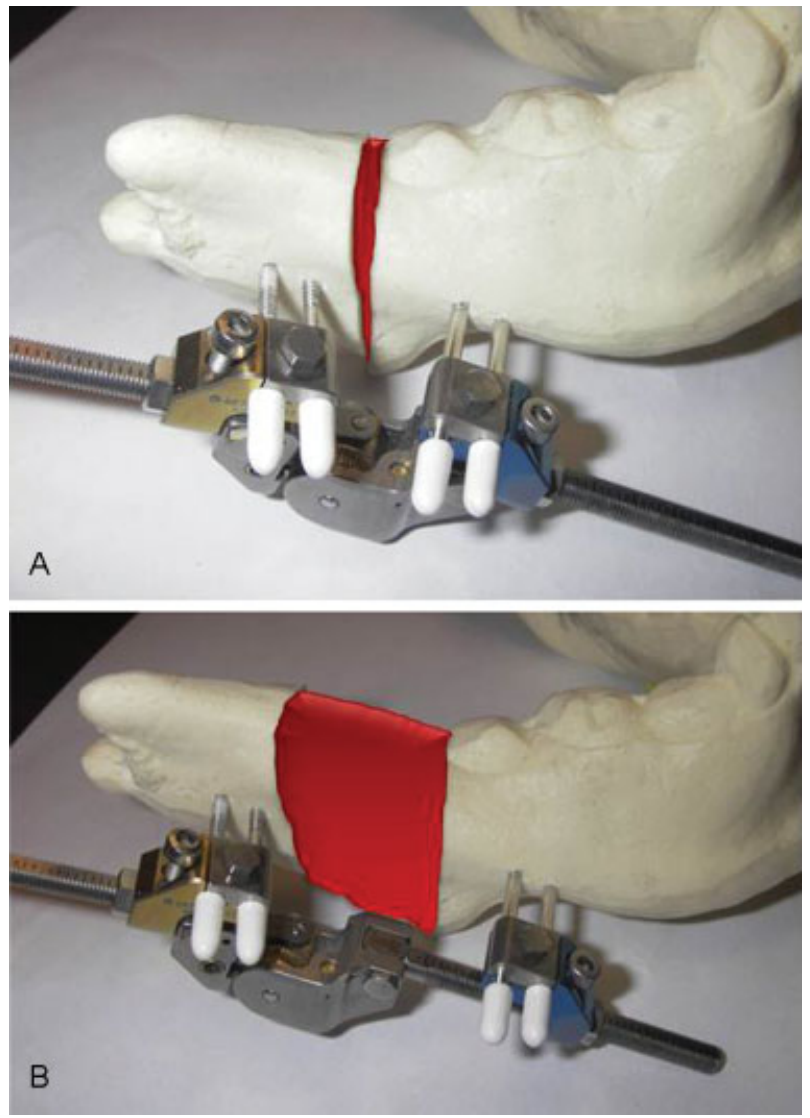

Fig. 2 A schematic using a medical model of the mandible demonstrating the concept behind distraction osteogenesis. An external device with percutaneous $k$-wires is shown here. The regenerate bone is depicted in red. (A) Initial osteotomy and placement of hardware. (B) Representation of bone growth after several minutes of activation.

\section{Epidemiology}

The birth prevalence of PRS varies by race and region. Historically, the estimated birth prevalence of PRS is between 0.5 and 1.2:10,000 live births. ${ }^{1}$ More recent data also suggest that the highest rate of isolated PRS is in whites $(2.1 / 10,000$ live births) and the lowest rate is in non-Hispanic blacks $(<0.5 / 10,000$ live births). Isolated PRS is more common in the Midwest (2.2/10,000 live births) and less common in the Northeast (1.2/10,000 live births). The rate of syndromic PRS is less variable across races and regions and is approximately $1.4 / 10,000$ live births. ${ }^{2}$ Rates of surgical airway intervention may also vary across regions; however, most case series demonstrate a consistent surgical airway intervention rate of approximately $40 \%$ in infants with PRS. ${ }^{3-5}$

\section{Embryology and Relevant Anatomy}

Congenital malformations of the mandible most commonly involve hypoplasia of the mandibular body, with or without associated abnormalities of the ramus, condyle, and temporomandibular joint. In 1969, Pruzansky reported a grading system for mandibular deficiency. He defined grade I as minimal hypoplasia of the mandible; grade II as a functional but deformed temporomandibular joint in which the condyle is displaced anteriorly and medially, and grade III as the absence of the ramus and glenoid fossa ${ }^{6}$ ( - Fig. 4). Other classification schemes have been proposed; however, the Pruzansky classification has been proven to be the most influential in regard to how these children are managed surgically.

\section{History of Mandibular Distraction Osteogenesis}

The concept of distraction osteogenesis was introduced by Codivilla $^{7}$ in 1905 and improved upon by Ilizarov in the 1950s, when the concept of bone lengthening was revisited in the context of treating leg length discrepancies. ${ }^{8}$ The first reported use of mandibular distraction in children with micrognathia was in 1992, when McCarthy et al used the 


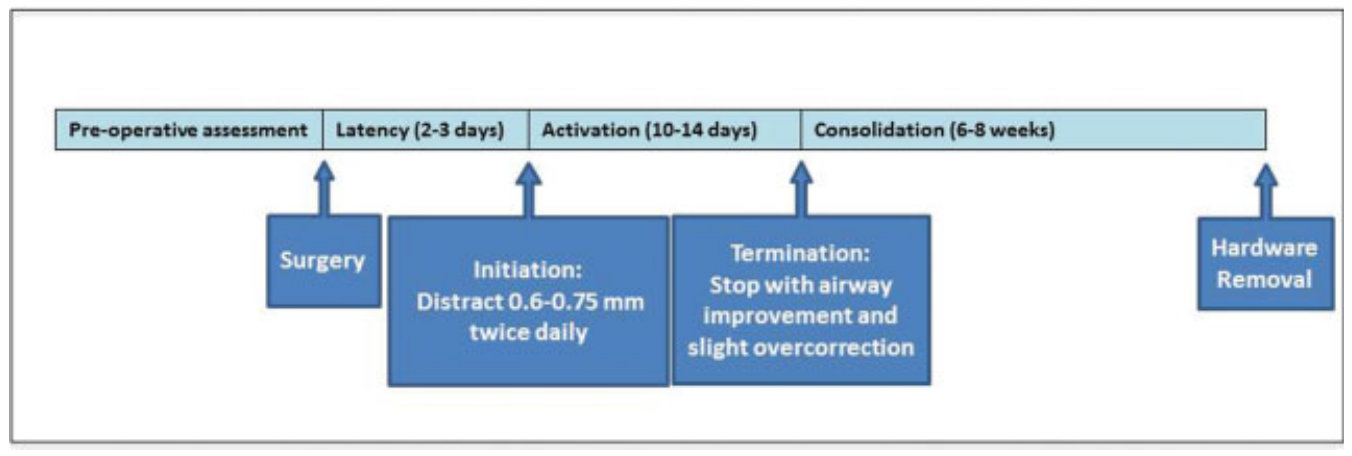

Fig. 3 The author's preferred timeline for neonatal mandibular distraction osteogenesis.
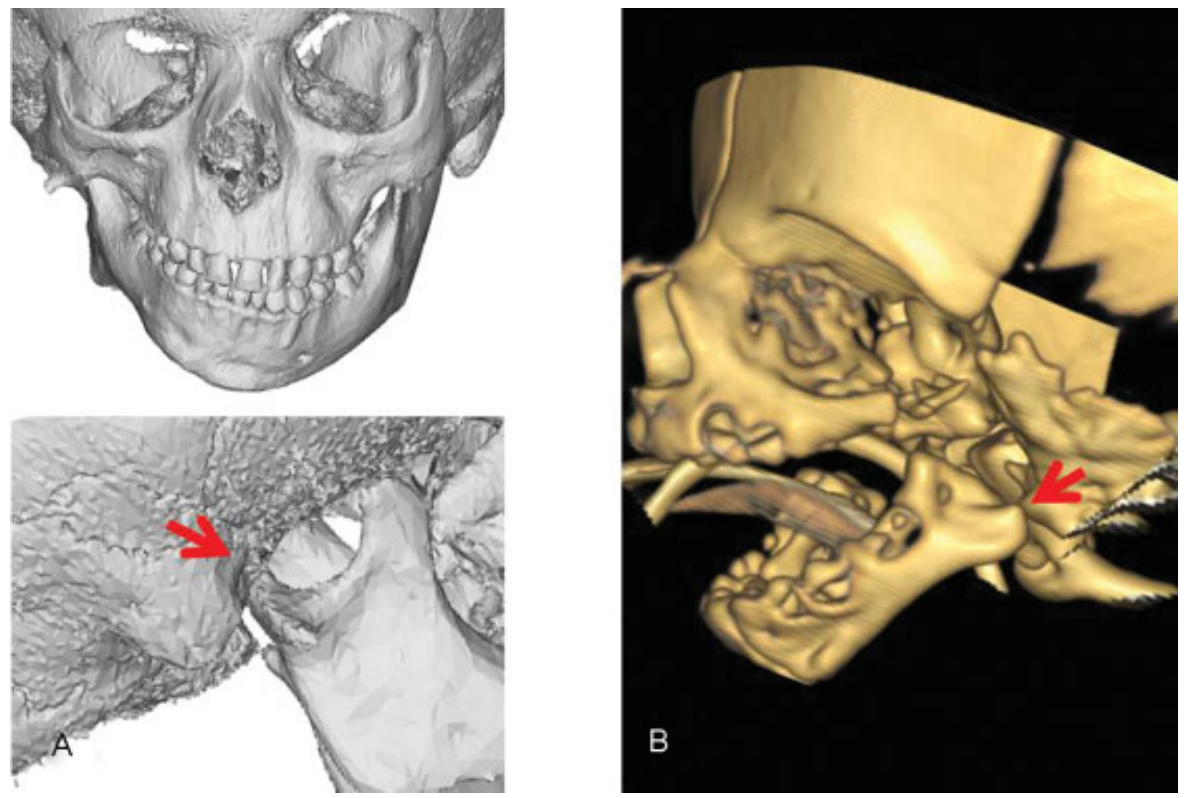

Fig. 4 (A) Pruzansky grade II malformation with a functional but deformed temporomandibular joint. (B) Pruzansky grade III malformation demonstrating absence of the ramus and glenoid fossa. Red arrow points to condyle.

technique to treat older children with mandibular deficiencies. ${ }^{9}$ In 1998, successful use of the technique was reported in a 14-week-old infant. ${ }^{10}$ By 2001, multiple additional reports had been published documenting the use of bilateral MDO for relieving upper airway obstruction in infancy. ${ }^{11,12}$ There is a growing body of literature pertaining to the positive longterm results of early bilateral MDO for relief of upper airway obstruction. ${ }^{13-19}$

\section{Limitations of Mandibular Distraction Osteogenesis}

Caution is advised in children with absent mandibular condyles, abnormal coronoid processes, and/or poorly defined glenoid fossae (Pruzansky grade III), as such children are not ideal MDO candidates. ${ }^{20}$ Many children with oculo-auriculo-vertebral spectrum, Treacher Collins syndrome, or Nager syndrome, for example, have an underlying disturbance in the mandibular growth center located just below the condyle, which may limit, if not prevent, a normal pace of mandibular growth. Additionally, these infants lack a well-defined glenoid fossa on the affected side(s). Therefore, if mandibular distraction is performed, the posterior mandibular segment may not engage properly against the skull base, thus preventing effective anterior advancement of the mandible with distraction of the mobile segments.

Costal cartilage grafting and creation of a pseudoarthrosis at the temporomandibular joint site allow for a means of addressing Pruzansky grade III deformities. ${ }^{21,22}$ Such procedures are not performed in infancy but rather later in childhood.

Conferring with a neonatologist, geneticist, and a pediatric neurologist prior to moving forward with mandibular distraction may avoid operating on a neurologically impaired child. Many investigators have noted that children with PRS who are also neurologically impaired are at risk for airway compromise from factors that are independent of glossoptosis. ${ }^{3-5,19,23-25}$ Mandibular distraction alone will not treat coexisting hypotonia, poor coordination, or chronic aspiration. For children with these comorbidities, tracheostomy and gastrostomy-tube placement allows for bypass of any and all sites of upper airway obstruction, 
improved pulmonary toilet, and maintenance of enteral nutrition.

\section{Preoperative Assessment: Evaluating Ventilation and Feeding}

Nonsurgical management of upper airway obstruction in children with PRS is always preferable and the decision to move forward with a surgical intervention remains controversial. In the most common scenario of mild to moderate or intermittent obstruction (episodic oxygen desaturations at rest or with feeds, signs of carbon dioxide retention and chronic respiratory acidosis on capillary blood gas, and inability to meet oral feeding goals), the author's philosophy is to start with side lying and prone positioning. If this fails to improve ventilation, placement of a nasopharyngeal airway or a custom oral appliance may relieve obstruction. ${ }^{26-29}$

The author relies primarily on feeding trends, obstructive events, carbon dioxide retention, and weight gain to determine which infants merit surgical management. When carbon dioxide levels increase into the 50s and bicarbonate levels rise (suggesting metabolic compensation of a chronic respiratory acidosis), a higher suspicion for chronic airway obstruction should exist. Polysomnography may also be performed. Prior to intervention, the airway should be assessed with bedside flexible laryngoscopy to rule out a synchronous airway lesion. The presence of an additional site of airway obstruction may influence the choice of surgical intervention. In instances of significant multilevel airway obstruction, for example, it may be prudent to move forward with tracheotomy.

\section{The Mandibular Distraction Procedure}

\section{Surgical Approaches and Device Selection}

The pediatric mandible may be approached surgically through an external or intraoral approach. In neonates, the former is more common. The external approach results in a 2- to 3-cm scar in the submandibular area, which may be avoided through a transoral procedure. Neonatal mandibular distraction may be accomplished with the use of either buried (internal) hardware or external devices, which are affixed to the mandible through percutaneous, bicortical k-wires. To allow for activation of an internal device, a portion of hardware (the activation arm) is externalized through a separate incision when buried distractors are used. This activation arm may be external (most common) or intraoral (-Fig. 5).

The advantages of using buried hardware are a secure and close approximation of the device to the mandible and avoidance of paramandibular scars from percutaneous kwires. Disadvantages include an inability to perform multivector distraction, inability to access the device for troubleshooting if mechanical failure is encountered, the need for preoperative computed tomography $(\mathrm{CT})$ with ionizing radiation to adequately plan vectors and precise placement of a
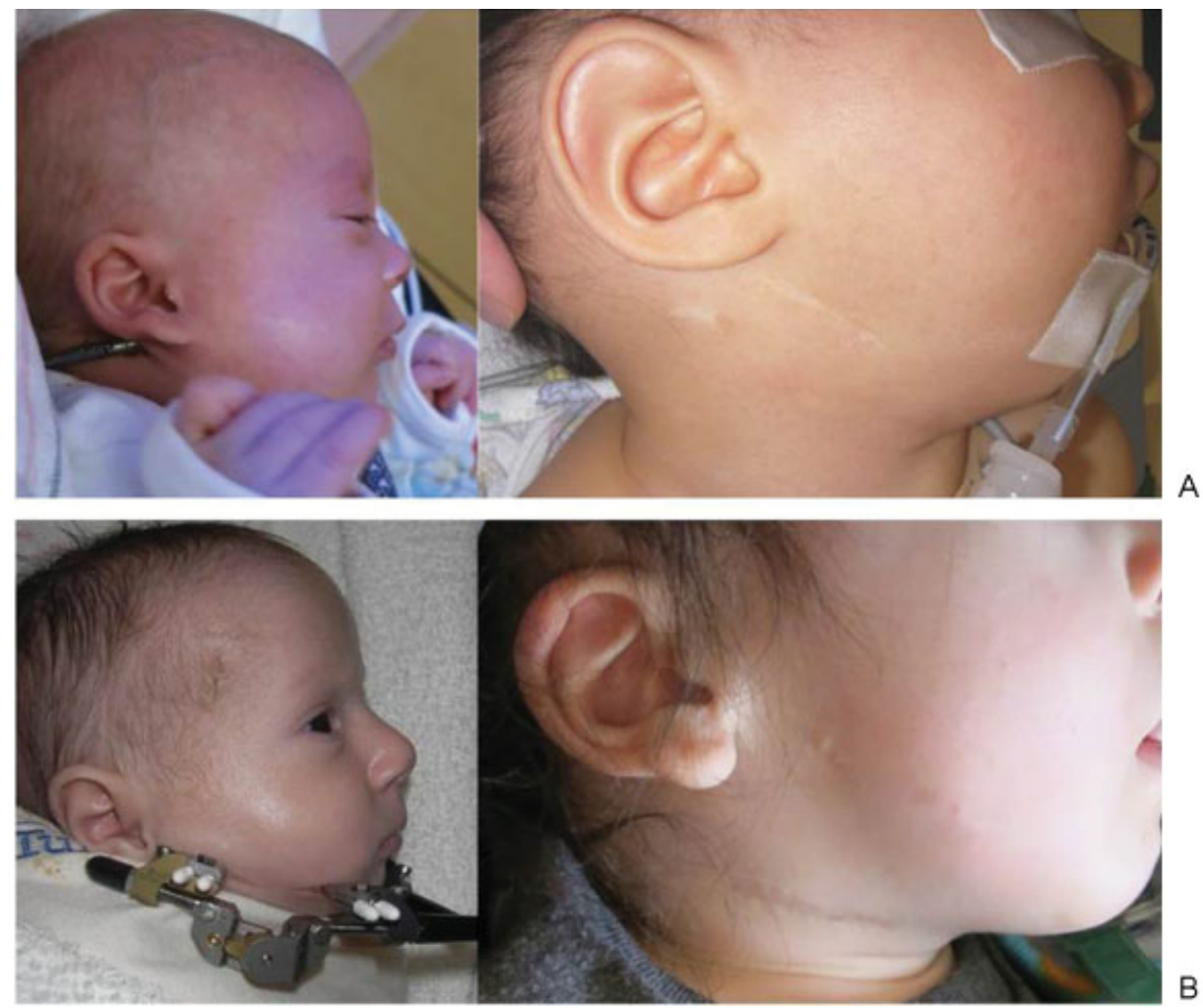

B

Fig. 5 (A) A buried, univector distractor and typical pattern of facial scarring. (B) An external, multivector distractor and typical pattern of facial scarring. 


\begin{tabular}{|c|c|c|c|}
\hline \multicolumn{2}{|l|}{$\begin{array}{l}\text { Buried Univector } \\
\text { Device }\end{array}$} & \multicolumn{2}{|l|}{$\begin{array}{l}\text { External Multivector } \\
\text { Device }\end{array}$} \\
\hline Advantages & Disadvantages & Advantages & Disadvantages \\
\hline $\begin{array}{l}\text { Less exposed } \\
\text { hardware, greater } \\
\text { stability }\end{array}$ & $\begin{array}{l}\text { Unable to inspect } \\
\text { hardware }\end{array}$ & $\begin{array}{l}\text { Easy to inspect } \\
\text { hardware }\end{array}$ & Less stable \\
\hline Less facial scarring & $\begin{array}{l}\text { Univector distraction, } \\
\text { potential asymmetry } \\
\text { and/or open bite }\end{array}$ & $\begin{array}{l}\text { Multivector } \\
\text { distraction, } \\
\text { immediate correction } \\
\text { of asymmetry and/or } \\
\text { open bite }\end{array}$ & Facial scars \\
\hline \multirow[t]{3}{*}{$\begin{array}{l}\text { Easier care during } \\
\text { consolidation }\end{array}$} & $\begin{array}{l}\text { Additional surgery for } \\
\text { removal }\end{array}$ & $\begin{array}{l}\text { Simple procedure for } \\
\text { removal }\end{array}$ & $\begin{array}{l}\text { More care required } \\
\text { during } \\
\text { consolidation }\end{array}$ \\
\hline & $\begin{array}{l}\mathrm{CT} \text { for precise vector } \\
\text { planning }\end{array}$ & $\begin{array}{l}\text { No imaging required } \\
\text { in most cases }\end{array}$ & \\
\hline & More expensive & Less expensive & \\
\hline
\end{tabular}

Fig. 6 A summary of the advantages and disadvantages of buried and external distraction devices.

single-plane device, and a more extensive operation for hardware removal following consolidation.

Advantages of external hardware include use of multidirectional devices which allow for immediate correction of open bite deformities or mandibular asymmetries during the activation process, easy access to the device for any troubleshooting, and ease of subsequent hardware removal (performed in minutes during a light sedation). With the exception of certain syndromic forms of PRS, preoperative CT is not necessary prior to mandibular distraction when external hardware is used. ${ }^{30}$ This saves a considerable amount of money and avoids exposing a newborn to radiation. Disadvantages unique to external hardware include a greater risk of injury to the inferior alveolar nerve or tooth buds during placement of bicortical k-wires, potential for device loosening, infection of percutaneous k-wires, and the presence of more conspicuous paramandibular scars (-Fig. 6).

\section{Risks of Surgery}

Complications of MDO may occur, regardless of the approach used. Operative complications include facial nerve injury, injury to the inferior alveolar nerve, incomplete mandibulotomy leading to inadequate activation, damage to the molar tooth buds, intraoperative and/or postoperative bleeding requiring transfusion, and infection. ${ }^{17}$ The length of the latency phase may be too short (preventing ossification of the regenerate) or too long (premature consolidation). During the activation phase, mandibular deformities such as asymmetry or development of an anterior open bite may occur. Infection of hardware through the exposed activation arms or percutaneous k-wires may develop and this may range from a minor cellulitis to frank osteomyelitis. Traction of soft tissues during activation may lead to facial nerve weakness, though this is usually transient. Even if an optimal result is obtained at the end of the activation phase, complications during the consolidation period may include mandibular regression with asymmetry or decreased projection with a relapse of airway and feeding symptoms; infection during this phase is also possible. While hardware removal is a simple process without complications when external devices are used, removal of buried hardware may prove to be a more extensive procedure. Scarring and repositioned anatomy within a previously operated field puts the facial nerve at risk, especially when accessing the mandibular ramus through a submandibular incision in an infant, a maneuver that requires aggressive soft tissue retraction over an underdeveloped mastoid tip.

Long-term complications following neonatal MDO include residual or recurrent obstructive sleep apnea and/or persistent or recurrent dysphagia, facial scarring, mandibular asymmetry, deformed or absent second molars, dentigerous cyst formation, and need for further mandibular procedures. ${ }^{13}$

\section{Description of Procedures}

\section{Bilateral Mandibulotomies and Placement of Distraction Devices}

Intervention is deferred until the infant reaches a minimum of $2.5 \mathrm{~kg}$. Optimal communication between pediatric anesthesia and pediatric otolaryngology providers is a must to assure safe management of a tenuous airway. Once nasotracheal intubation has been secured, the pediatric anesthesia team may establish a central line if a peripheral intravenous central catheter has not already been placed. For an external approach, a 2- to $3-\mathrm{cm}$ incision is planned within a relaxed skin tension line of the neck, at least one finger-breadth below

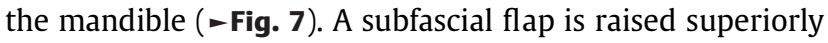
over the submandibular gland to protect the marginal 


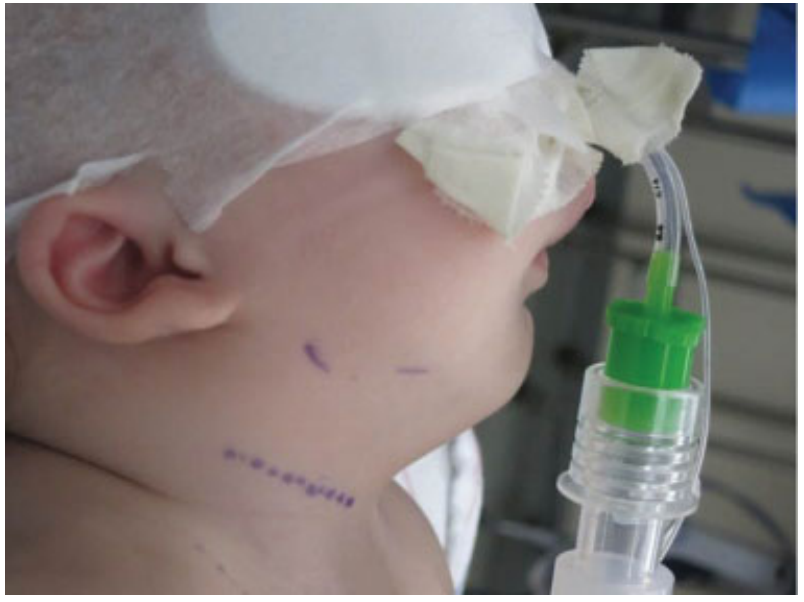

Fig. 7 Operative markings including planned submandibular incision.

mandibular branch of the facial nerve. The periosteum is incised along the inferior edge of the mandibular body and angle allowing for elevation in a subperiosteal plane over the buccal and lingual surfaces of the mandible. The author prefers a vertical mandibulotomy anterior to the angle in neonates ( - Fig. 8); however, an inverted L osteotomy may be performed posterior to the dental follicles. An outer corticotomy is made using a $1.2-\mathrm{mm}$ side cutting dental drill or a piezoelectric device. The mandibulotomy is not completed at this time.

\section{External Hardware}

When using an external multidirectional distraction device, the author uses distractors made by DePuy Synthes (West Chester, PA) (no proprietary affiliation or conflict of interest). The k-wires are inserted at an angle that is perpendicular to the midsagittal plane and not necessarily perpendicular to the surface of the mandible (-Fig. 9). The mandibulotomy is completed using a combination of angled

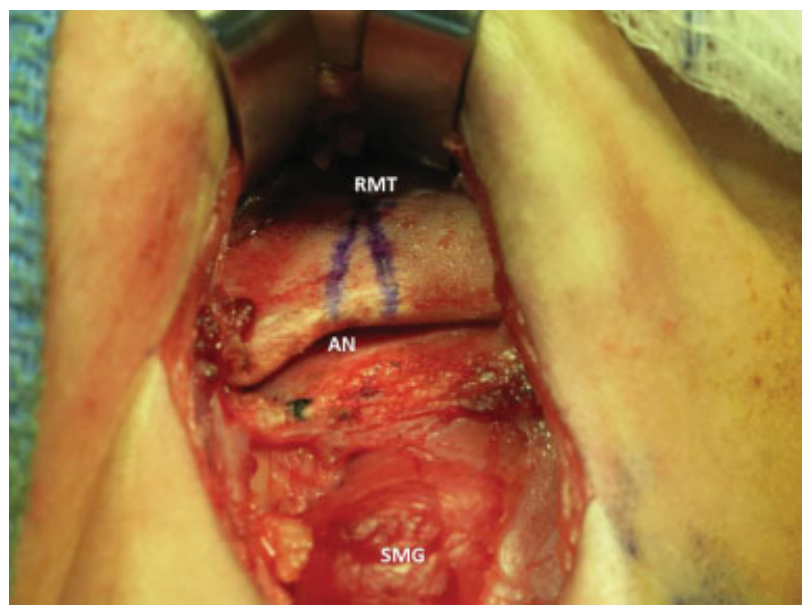

Fig. 8 Planning vertical mandibulotomy: right hemimandible depicted. In this case, the anterior marking was used. AN, antegonial notch; RMT, retromolar trigone; SMG, submandibular gland.

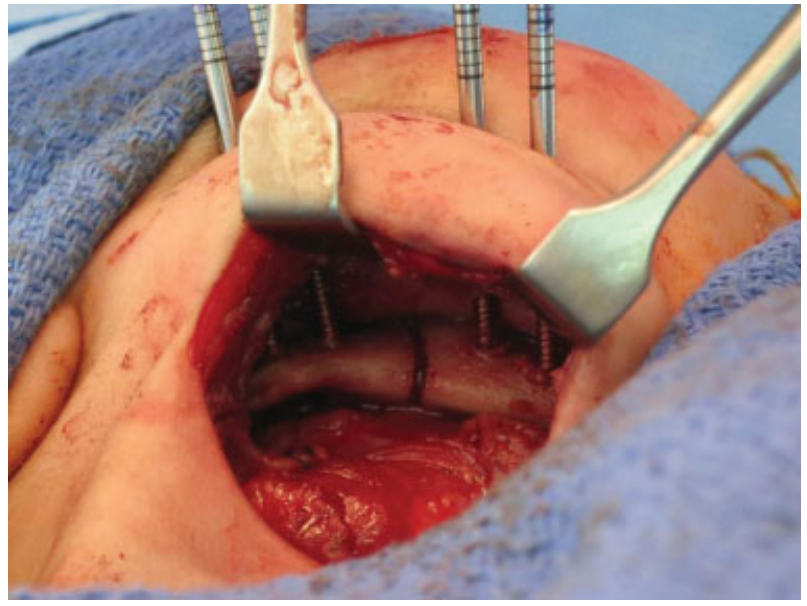

Fig. 9 Placement of percutaneous k-wires perpendicular to the midsagittal plane (external multivector distractor used).

and straight osteotomes. A trial of linear distraction is performed to assure a complete mandibulotomy and rule out green sticking. With the soft tissue on stretch, the anatomic continuity of the inferior alveolar nerve may be confirmed ( $\mathbf{- F i g . ~ 1 0 ) . ~ T h e ~ b o n e ~ s e g m e n t s ~ a r e ~ t h e n ~ r e t u r n e d ~ t o ~ t h e i r ~}$ resting, anatomic position. Excess k-wires are cut and silicone caps applied over their sharp ends.

\section{Buried Hardware}

The author's buried linear distractor of choice for newborns is the KLS Martin center-driven, pediatric Zurich distractor (South Jacksonville, FL) (no proprietary affiliation or conflict of interest). For unidirectional devices, planning the vector of distraction is critical for assuring mandibular symmetry and avoiding development of an open bite deformity. Children may undergo CT scanning preoperatively followed by precise vector analysis using virtual surgical planning software (-Fig. 11). In toddlers and older children, a custom curvilinear buried device may be used (DePuy Synthes, West Chester,

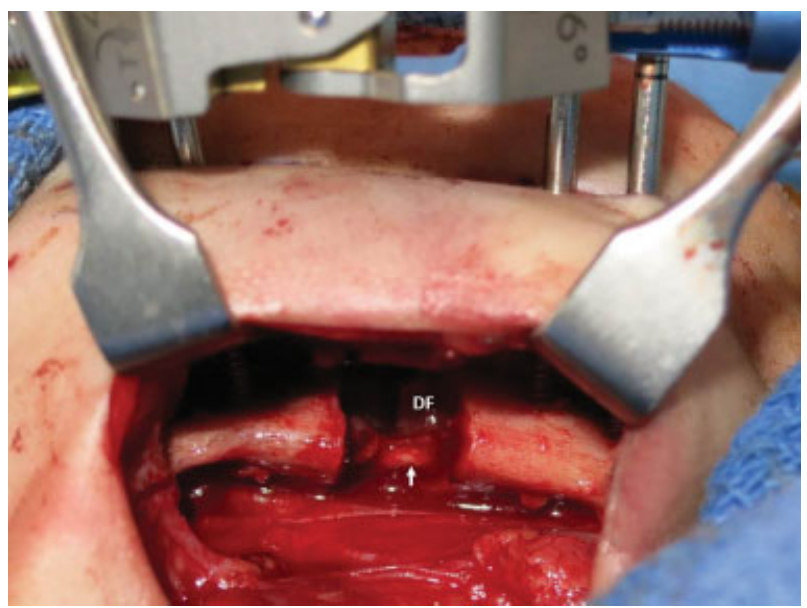

Fig. 10 During an intraoperative trial of distraction, which is performed to ensure completion of the osteotomy, the inferior alveolar nerve (arrow) and a dental follicle (DF) can be seen within the mandibulotomy. 

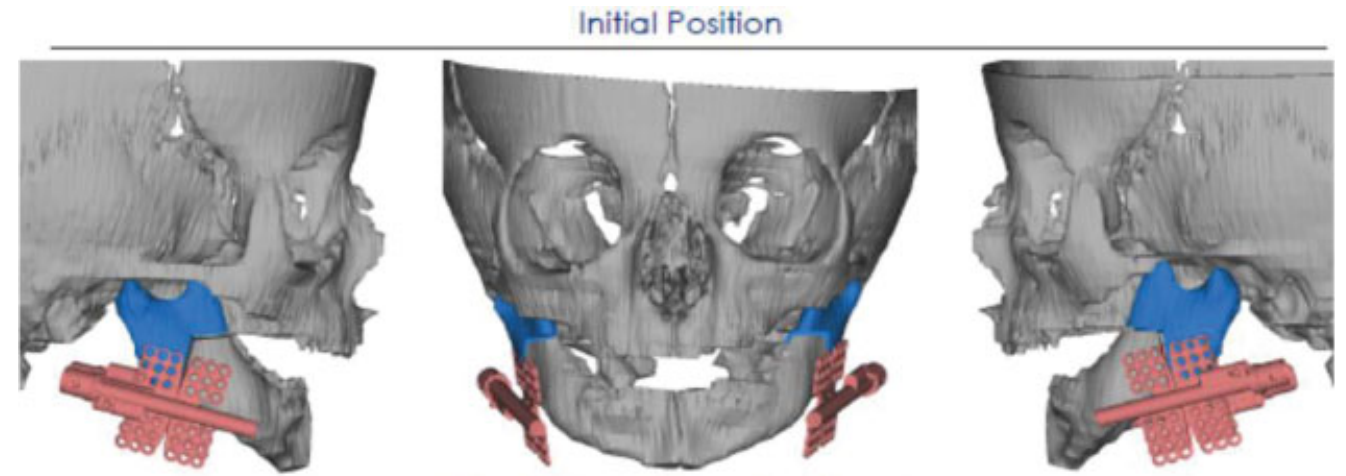

Final Position Distracted 10mm
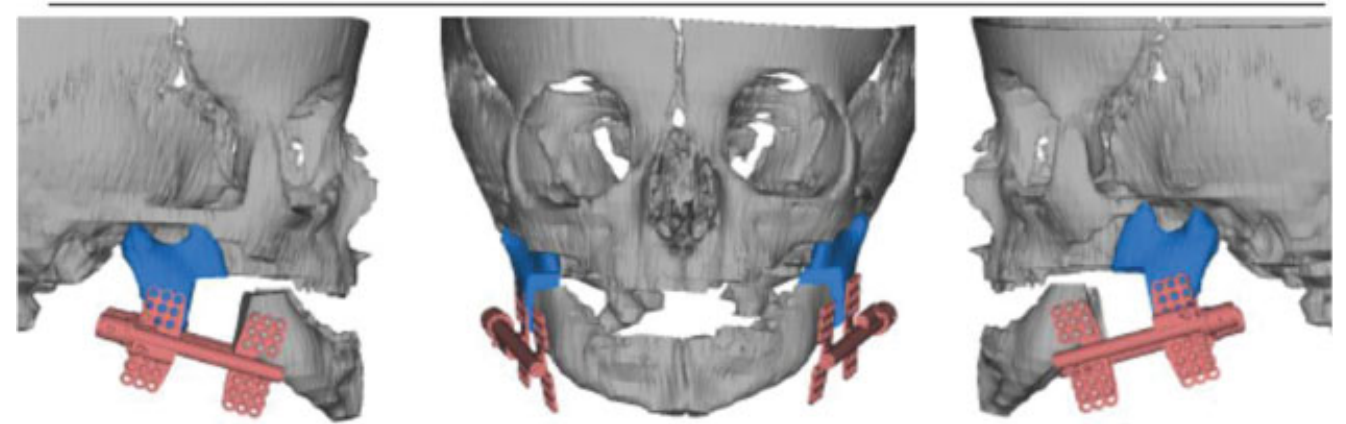

Fig. 11 An example of a commercially available, virtual surgical planning report, which is customized for each patient.
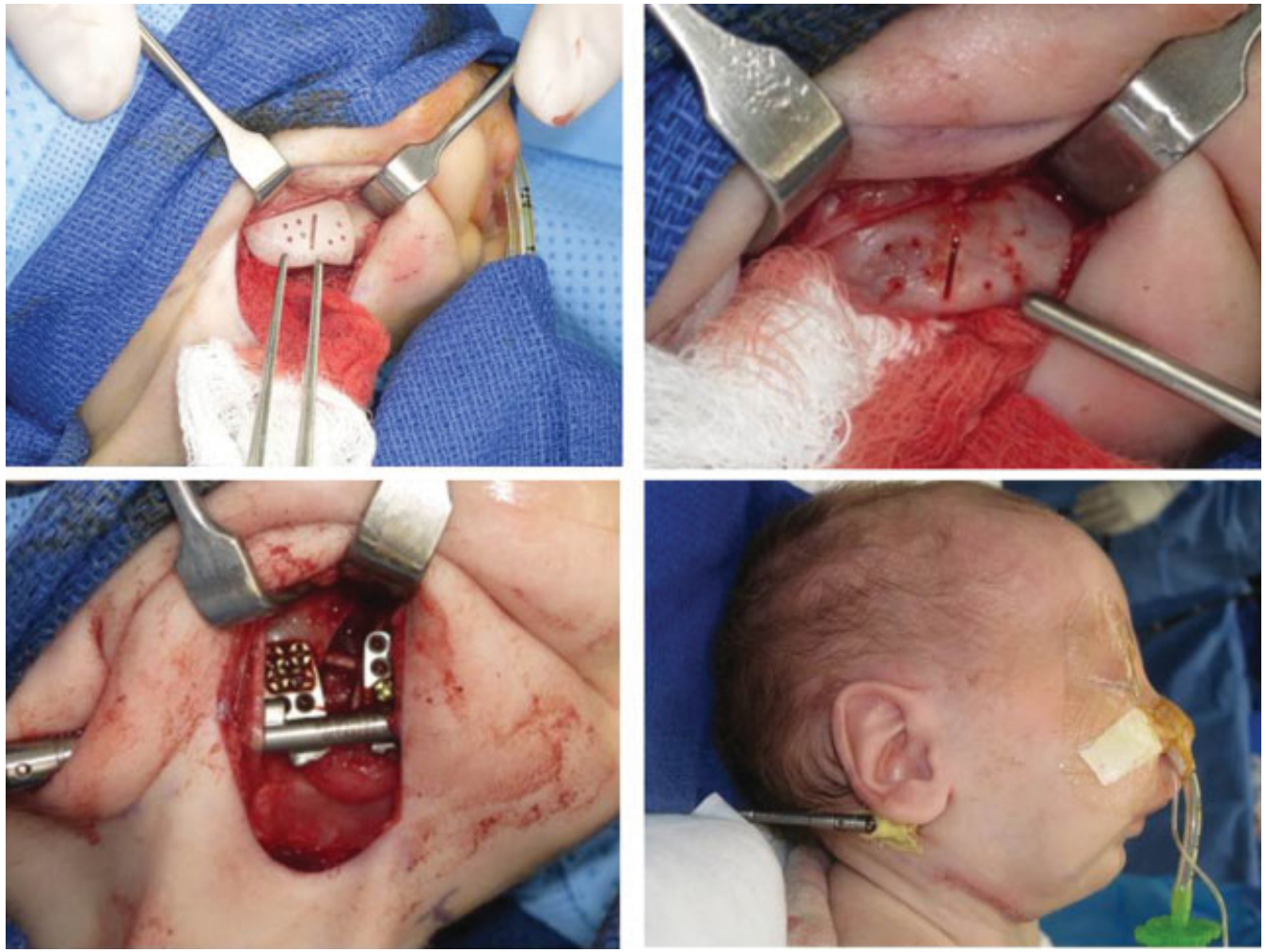

Fig. 12 Use of a buried univector device in a neonate, right hemimandible depicted. Precise hardware placement is guided by custom cutting guides (upper left). These guides are based on data derived from a virtual surgical planning report such as the one presented in $\boldsymbol{\sim}$ Fig. $\mathbf{1 0}$. During a trial distraction, the inferior alveolar nerve is seen (bottom left). 
PA), allowing for curvilinear activation, which closes any open bite deformity that would otherwise develop during the course of linear distraction. Cutting guides may be used to precisely place the hardware (-Fig. 12). High profile, bicortical screws are placed, as these are easier to find and remove during subsequent reexploration after consolidation. The mandibulotomy is completed and a trial distraction is performed to ensure completion of the osteotomy as mentioned earlier. The device is then returned into resting position and the ratchet engaged.

\section{Closure}

The submandibular wound is checked for hemostasis, irrigated, and closed with 4-0 Vicryl, 6-0 fast absorbing suture, and skin glue. The k-wires or activation arm serves as passive drains.

\section{Postoperative Care}

The author prefers to leave neonates and infants intubated and sedated for several days. A combination of agents including morphine, midazolam, lorazepam, vecuronium, and dexmedetomidine may be used to assure a period of immobilization while limiting narcotic withdrawal symptoms. ${ }^{31}$ With use of this protocol, children are usually off of all sedating medications by postoperative day 10 . A size 1 laryngeal mask airway and nasal trumpets are left at the bedside.

\section{Latency Period}

Variations exist in the length of latency for neonatal and infant mandibular distraction. The author uses a 48- to 60hour time period for the latency phase. Intravenous cephazolin is maintained throughout the latency and subsequent activation periods.

\section{Activation Period}

In infants and newborns, the author performs twice daily distractions, ideally close to 12 hours apart. With the external distraction system, activation occurs at a rate of $0.75 \mathrm{~mm}$ twice daily, amounting to a rate of $1.5 \mathrm{~mm}$ each day. With the KLS buried system, the rate is slower and proceeds at $0.6 \mathrm{~mm}$ twice daily, or $1.2 \mathrm{~mm}$ each day. Intravenous cephazolin is continued and then transitioned to enteral cephalexin to maintain antibiotic prophylaxis throughout the activation period. The infant is left intubated and sedated until postoperative days 5 to 6 , at which point the mandible has been advanced $5 \mathrm{~mm}$, a distance that has been shown to be enough to break the seal of the tongue base against the posterior pharyngeal wall. $^{11}$

Oral feeding is started once sedation has lightened and this is advanced as tolerated. The goal should be to achieve slight overcorrection, bringing the infant into end-to-end occlusion based on the alveolar ridges (-Fig. 13). In female infants, distraction may cease just prior to end-on occlusion to avoid the masculine characteristic of prognathism. Once activation has ended, usually postoperative days 10 to 14 , antibiotic prophylaxis is discontinued and discharge planning initiated.

\section{Consolidation Phase}

Outpatient services beyond weight checks are rarely needed following neonatal mandibular distraction, as with correction of the airway, monitoring and tube feedings are usually no longer necessary. Parents are instructed on pin care. The author prefers a consolidation phase that is at least three times the length of the activation phase to ensure optimal ossification of the regenerate.

For external devices, an outpatient procedure for hardware removal under a light anesthetic (mask or laryngeal mask airway) is planned for 6 weeks following completion of the activation phase. This is a percutaneous procedure that takes 2 or 3 minutes and results in minimal, if any, blood loss.

In cases with buried hardware, a more extensive operation is necessary. This takes place under general anesthesia
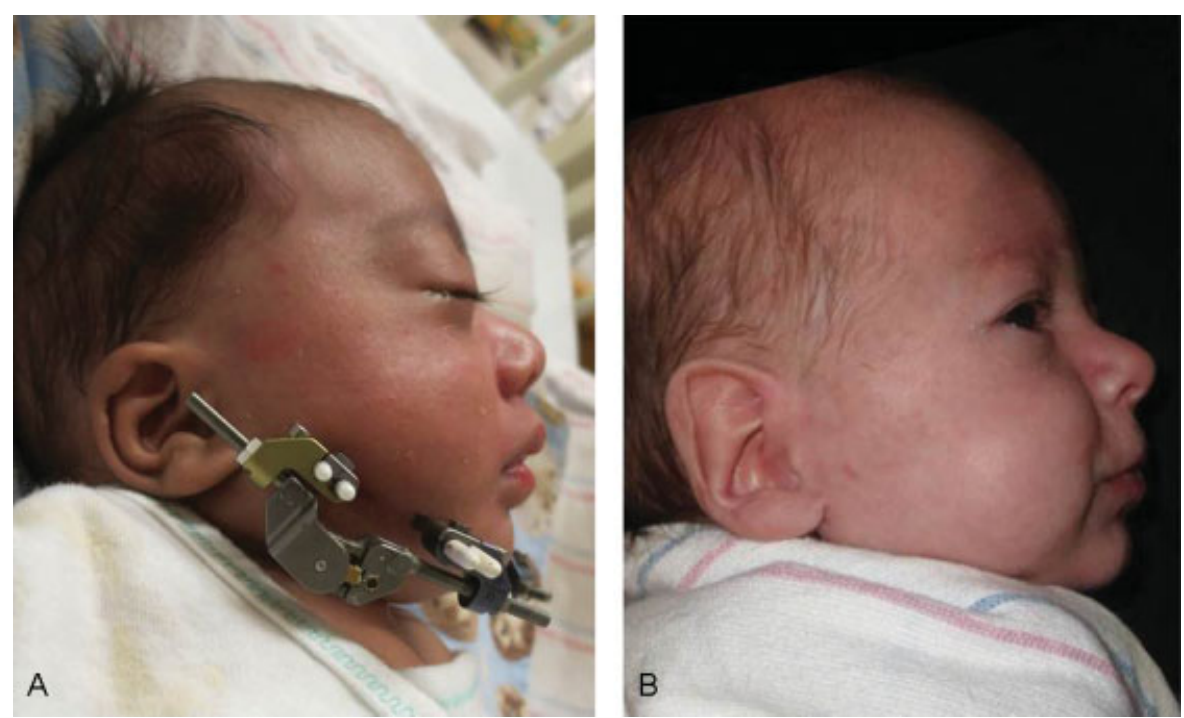

Fig. 13 Appearance at the completion of activation, over-correction is apparent in anticipation of some mild regression during the consolidation phase. (A) Multivector external device. (B) Univector buried device. 


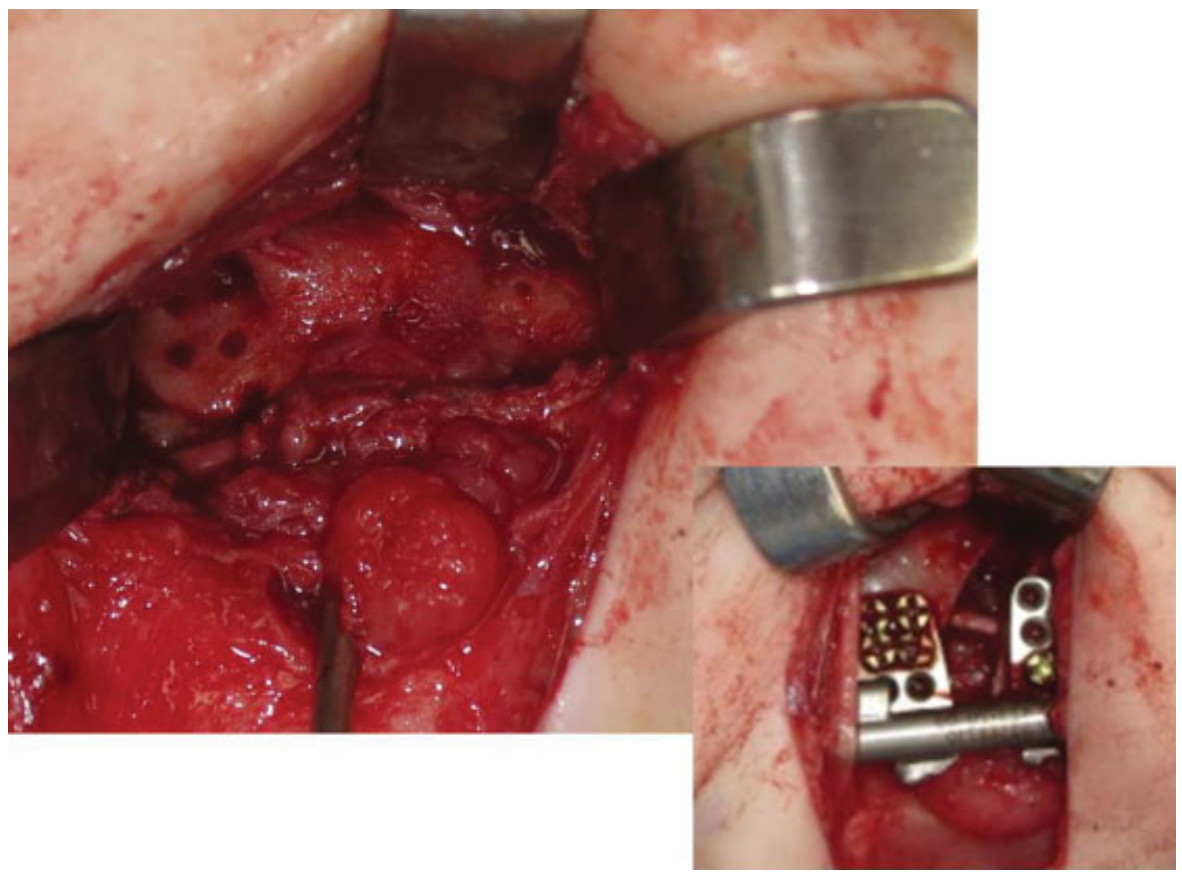

Fig. 14 Inspection of the regenerate following 6 weeks of consolidation after distraction using a buried univector device. Lower inset shows trial distraction during initial surgery on the same patient.

and excision of hypertrophic scarring at the activation arm site may be performed with hardware removal. Direct inspection of the regenerate bone is performed at this time (-Fig. 14). The child is admitted overnight and discharged the following day.

\section{Outcomes}

In spite of the significant risk involved in neonatal mandibular distraction, this technique has gained wide acceptance among pediatric otolaryngologists and plastic craniofacial surgeons in the United States and beyond. Children who undergo MDO tend to do well clinically, especially in regard to airway and feeding outcomes. ${ }^{32}$ Quality-of-life studies and radiographic

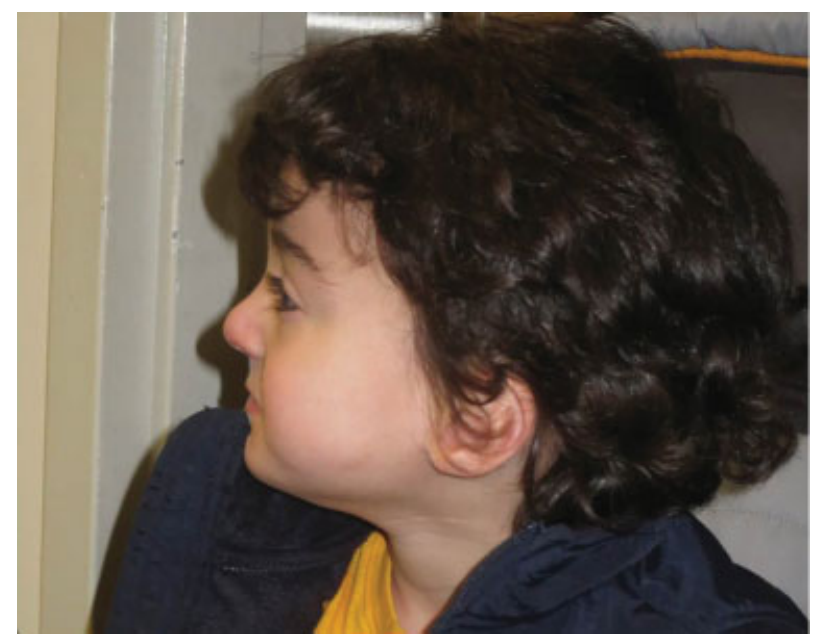

Fig. 15 Appearance of facial scars following neonatal mandibular distraction with an external multivector device at the 4-year interval. swallowing evaluations following MDO also demonstrate a significant benefit over alternative interventions such as TLA or neonatal tracheotomy. ${ }^{33,34}$

Multiple series have been published identifying the shortand long-term complications of MDO in general. Overall, longterm outcomes of neonatal mandibular distraction are still in evolution; however, a 2011 study of 19 children who underwent neonatal mandibular distraction had an average length of follow-up of 5.6 years and suggested that this procedure allows for a sustained correction of airway and feeding difficulties that persists into early childhood ${ }^{19}$ (- Fig. 15).

With potential long-term complications related to tooth malformation and mild malocclusion, the importance of multidisciplinary craniofacial follow-up after MDO is clear. All children with PRS require regular follow-up with pediatric dentistry, orthodontics, and oral surgery regardless of any history of surgical intervention, and children undergoing early mandibular distraction are no exception. The purpose of the MDO procedure is to avoid a tracheotomy and a feeding gastrostomy tube. Additional benefits, such as improved occlusion and mandibular profile, are only secondary goals of MDO. The primary aim of neonatal MDO is to ameliorate breathing and feeding difficulty in the neonatal period. Therefore, subsequent use of orthodontic appliances and secondary aesthetic procedures, such as LeFort 1 osteotomy and sliding genioplasty, may still be indicated in adolescence in these patients.

Level of Evidence

Virtually all of the literature supporting early MDO is retrospective and most studies are single-center case series. Consensus regarding the diagnosis and treatment 
of neonates with PRS remains elusive, and the long-term outcomes of neonatal surgical interventions remain to be seen. ${ }^{35}$ Given the relative rarity of PRS and the multiple variables that factor into the clinical decision to move forward with mandibular distraction (regional variations in the management of PRS, surgeon and parental influences on choice of intervention), it has been difficult to improve upon the existing level 4 evidence. ${ }^{36}$

A 2008 meta-analysis including 646 adult and pediatric bilateral mandibular distraction cases reported that the surgery was effective in preventing tracheostomies for 91.3\% of neonates or infants with respiratory distress. ${ }^{37}$ However, a recent systematic review of complication rates following distraction osteogenesis of the mandible for congenital malformations in adults, children, and infants suggested that inferior alveolar nerve neurosensory disturbances, minor infection, device failure, anterior open bite, permanent dental damage, and skeletal relapse were the most common postoperative complications, with permanent injuries seen in as many as $9.6 \%$ of cases. ${ }^{38}$ The outcomes of each of these studies are confounded by the heterogeneity of their patient populations. A coordinated multicenter study with a standardized diagnostic and treatment algorithm has been recommended to develop evidence for the diagnosis and treatment of neonates with PRS. ${ }^{35}$

\section{References}

1 Genisca AE, Frías JL, Broussard CS, et al; National Birth Defects Prevention Study. Orofacial clefts in the National Birth Defects Prevention Study, 1997-2004. Am J Med Genet A 2009;149A(6): $1149-1158$

2 Scott AR, Mader NS. Regional variations in the presentation and surgical management of Pierre Robin sequence. Laryngoscope 2014;124(12):2818-2825

3 Evans AK, Rahbar R, Rogers GF, Mulliken JB, Volk MS. Robin sequence: a retrospective review of 115 patients. Int J Pediatr Otorhinolaryngol 2006;70(6):973-980

4 Kirschner RE, Low DW, Randall P, et al. Surgical airway management in Pierre Robin sequence: is there a role for tongue-lip adhesion? Cleft Palate Craniofac J 2003;40(1):13-18

5 Meyer AC, Lidsky ME, Sampson DE, Lander TA, Liu M, Sidman JD. Airway interventions in children with Pierre Robin sequence. Otolaryngol Head Neck Surg 2008;138(6):782-787

6 Figueroa AA, Pruzansky S. The external ear, mandible and other components of hemifacial microsomia. J Maxillofac Surg 1982 Nov;10(4):200-211

7 Codivilla A. The classic: on the means of lengthening, in the lower limbs, the muscles and tissues which are shortened through deformity. Clin Orthop Relat Res 2008;466(12): 2903-2909

8 Ilizarov GA. The tension-stress effect on the genesis and growth of tissues. Part I. The influence of stability of fixation and soft-tissue preservation. Clin Orthop Relat Res 1989;(238): 249-281

9 McCarthy JG, Schreiber J, Karp N, Thorne CH, Grayson BH. Lengthening the human mandible by gradual distraction. Plast Reconstr Surg 1992;89(1):1-8, discussion 9-10

10 Cohen SR, Simms C, Burstein FD. Mandibular distraction osteogenesis in the treatment of upper airway obstruction in children with craniofacial deformities. Plast Reconstr Surg 1998;101(2): 312-318
11 Denny AD, Talisman R, Hanson PR, Recinos RF. Mandibular distraction osteogenesis in very young patients to correct airway obstruction. Plast Reconstr Surg 2001;108(2):302-311

12 Sidman JD, Sampson D, Templeton B. Distraction osteogenesis of the mandible for airway obstruction in children. Laryngoscope 2001;111(7):1137-1146

13 Tibesar RJ, Scott AR, McNamara C, Sampson D, Lander TA, Sidman JD. Distraction osteogenesis of the mandible for airway obstruction in children: long-term results. Otolaryngol Head Neck Surg 2010;143(1):90-96

14 Lin SY, Halbower AC, Tunkel DE, Vanderkolk C. Relief of upper airway obstruction with mandibular distraction surgery: Longterm quantitative results in young children. Arch Otolaryngol Head Neck Surg 2006;132(4):437-441

15 Kleine-Hakala M, Hukki J, Hurmerinta K. Effect of mandibular distraction osteogenesis on developing molars. Orthod Craniofac Res 2007;10(4):196-202

16 McCarthy JG, Katzen JT, Hopper R, Grayson BH. The first decade of mandibular distraction: lessons we have learned. Plast Reconstr Surg 2002;110(7):1704-1713

17 van Strijen PJ, Breuning KH, Becking AG, Perdijk FB, Tuinzing DB. Complications in bilateral mandibular distraction osteogenesis using internal devices. Oral Surg Oral Med Oral Pathol Oral Radiol Endod 2003;96(4):392-397

18 Stelnicki EJ, Lin WY, Lee C, Grayson BH, McCarthy JG. Long-term outcome study of bilateral mandibular distraction: a comparison of Treacher Collins and Nager syndromes to other types of micrognathia. Plast Reconstr Surg 2002;109(6):1819-1825, discussion 1826-1827

19 Scott AR, Tibesar RJ, Lander TA, Sampson DE, Sidman JD. Mandibular distraction osteogenesis in infants younger than 3 months. Arch Facial Plast Surg 2011;13(3):173-179

20 Kaban LB, Moses MH, Mulliken JB. Surgical correction of hemifacial microsomia in the growing child. Plast Reconstr Surg 1988;82(1): 9-19

21 Goerke D, Sampson DE, Tibesar RJ, Sidman JD. Rib reconstruction of the absent mandibular condyle in children. Otolaryngol Head Neck Surg 2013;149(3):372-376

22 Perrott DH, Umeda H, Kaban LB. Costochondral graft construction/ reconstruction of the ramus/condyle unit: long-term follow-up. Int J Oral Maxillofac Surg 1994;23(6, Pt 1):321-328

23 Pasyayan HM, Lewis MB. Clinical experience with the Robin sequence. Cleft Palate J 1984;21(4):270-276

24 Caouette-Laberge L, Bayet B, Larocque Y. The Pierre Robin sequence: review of 125 cases and evolution of treatment modalities. Plast Reconstr Surg 1994;93(5):934-942

25 Tomaski SM, Zalzal GH, Saal HM. Airway obstruction in the Pierre Robin sequence. Laryngoscope 1995;105(2):111-114

26 Pielou WD, Allen A. The use of an obturator in the management of the Pierre Robin syndrome. Dent Pract Dent Rec 1968;18(5): 169-172

27 Oktay H, Baydaş B, Ersöz M. Using a modified nutrition plate for early intervention in a newborn infant with Pierre Robin sequence: a case report. Cleft Palate Craniofac J 2006;43(3): 370-373

28 Bacher M, Sautermeister J, Urschitz MS, Buchenau W, Arand J, Poets CF. An oral appliance with velar extension for treatment of obstructive sleep apnea in infants with Pierre Robin sequence. Cleft Palate Craniofac J 2011;48(3):331-336

29 Parhizkar N, Saltzman B, Grote K, et al. Nasopharyngeal airway for management of airway obstruction in infants with micrognathia. Cleft Palate Craniofac J 2011;48(4):478-482

30 Mingo K, Lander TA, Sampson DE, Tibesar RJ, Sidman JD, Scott AR. Use of external distraction devices eliminates the need for preoperative computed tomography in infants with isolated Pierre Robin sequence. JAMA Facial Plast Surg 2015;Nov 5:1-6

31 Fauman KF, Durand C, Durgham R, Vecchiotti MA, Scott AR. A sedation protocol limiting length of stay following airway 
surgery in infants and children. Laryngoscope 2015;125(9): 2216-2219

32 Lidsky ME, Lander TA, Sidman JD. Resolving feeding difficulties with early airway intervention in Pierre Robin Sequence. Laryngoscope 2008;118(1):120-123

33 Hong P, Brake MK, Cavanagh JP, Bezuhly M, Magit AE. Feeding and mandibular distraction osteogenesis in children with Pierre Robin sequence: a case series of functional outcomes. Int J Pediatr Otorhinolaryngol 2012;76(3): 414-418

34 Hong P, McNeil M, Kearns DB, Magit AE. Mandibular distraction osteogenesis in children with Pierre Robin sequence: impact on health-related quality of life. Int J Pediatr Otorhinolaryngol 2012; 76(8):1159-1163
35 Bookman LB, Melton KR, Pan BS, et al. Neonates with tongue-based airway obstruction: a systematic review. Otolaryngol Head Neck Surg 2012;146(1):8-18

36 Paes EC, Mink van der Molen AB, Muradin MS, et al. A systematic review on the outcome of mandibular distraction osteogenesis in infants suffering Robin sequence. Clin Oral Investig 2013;17(8): $1807-1820$

37 Ow AT, Cheung LK. Meta-analysis of mandibular distraction osteogenesis: clinical applications and functional outcomes. Plast Reconstr Surg 2008;121(3):54e-69e

38 Verlinden CR, van de Vijfeijken SE, Tuinzing DB, Jansma EP, Becking AG, Swennen GR. Complications of mandibular distraction osteogenesis for developmental deformities: a systematic review of the literature. Int J Oral Maxillofac Surg 2015;44(1):44-49 